\title{
Social Determinants of Stroke as Related to Stress at Work among Working Women: A Literature Review
}

\author{
Susanna Toivanen \\ Centre for Health Equity Studies (CHESS), Stockholm University and Karolinska Institutet, 10691 Stockholm, Sweden \\ Correspondence should be addressed to Susanna Toivanen, susanna.toivanen@chess.su.se
}

Received 25 August 2012; Accepted 25 October 2012

Academic Editor: Isabela M. Benseñor

Copyright () 2012 Susanna Toivanen. This is an open access article distributed under the Creative Commons Attribution License, which permits unrestricted use, distribution, and reproduction in any medium, provided the original work is properly cited.

In adult life, many of the social determinants of health are connected to working life. Yet, our knowledge of the role of work-related factors for the risk of stroke is fairly limited. In contemporary occupational health research, the Demand-Control Model (DCM) is frequently used to measure work stress. Previous literature reviews of the association of work stress and cardiovascular disease (CVD) do not include stroke as a specific outcome. Results regarding work stress and the risk of CVD are less evident in working women. With the focus on working women, the purpose of the present paper was to review the current research into the DCM in relation to stroke and to scrutinize potential gender differences. A literature search was performed and eight studies from three countries were identified. Based on the reviewed studies, there is some evidence that high psychological demands, low job control, and job strain are associated with increased stroke risk in women as well as in men. Any major reduction in deaths and disability from stroke is likely to come from decreasing social inequalities in health, and reducing work stress has a potential to contribute to a reduced risk of stroke in working populations.

\section{Introduction}

Social determinants of health, that is, those conditions under which people are born, live, work, and grow old, shape population health in a systematic way [1]. Unequal distribution of and access to resources such as power, education, income, goods, and services influence social inequalities in health between countries and between groups of people within countries. In adult life, many of the social determinants of health are connected to working life. Both employment conditions and adverse work environments contribute to social inequalities in health, and these conditions are unequally distributed across occupational classes and women and men in working populations [2]. Labor markets are clearly segregated by gender meaning that women and men usually work in different industrial sectors with different types of work environments. More women than men have a low occupational class and the share of work stress is usually higher in women's jobs [3]. Yet, our knowledge of associations of work related factors and the risk of stroke is fairly limited [4-6].
There is a clear social gradient in stroke mortality and morbidity as lower socioeconomic groups worldwide have consistently higher rates of stroke than higher socioeconomic groups [7]. A fourth of all stroke events occur among people of working age ( $<65$ years of age), and the consequences with regard to production loss, sickness absence, disability pension, and premature death are considerable $[5,8]$. Worldwide, stroke is more common among men, but women are more severely ill [9]. Many aspects of stroke are similar in women and men, including clinical presentation and distribution of the main subtypes and risk factors [10]. However, women with a heavy risk factor burden are more likely to suffer stroke than men with the same burden [11]. Moreover, there is evidence that women are not offered acute stroke treatment as frequently as men and that women die twice more frequently from stroke than men $[11,12]$.

Large international studies have identified psychosocial stress as one of the ten main modifiable risk factors for stroke [13]. For people of working age, stressors originating 
in the psychosocial work environment are shown to be particularly harmful for cardiovascular health [14]. The psychosocial work environment includes all aspects of the design and management of work, and its social and organizational context, that have the potential for causing psychological or physical harm among employees. Targeted interventions aimed at reducing psychosocial stress at work could therefore be away of combating stroke among working populations.

The Demand-Control Model (DCM) is one of the most commonly used models of psychosocial stress at work. DCM focuses on situational workplace characteristics in terms of psychological demands and job control and their influence on employees' health and lifestyles [15]. Psychological demands refer to time pressure, mental load, and coordination responsibilities. Job control (decision latitude) comprises two components: skill discretion and decision authority. Skill discretion refers to the possibility to use one's initiative and skills in the job. Decision authority is a socially agreed upon form of control over job performance, allowing the employee to decide how and when the job is done. Different combinations of demands and job control result in four specific work situations: active (high demands and high control), job strain (high demands and low control), passive (low demands and low control), and low strain (low demands and high control). Job strain is hypothesized to be the most stressful work situation because it limits an individual's autonomy and sense of control while the pressure is continuous, and therefore optimal coping is hampered [16]. Frequent and/or long-lasting exposure to job strain influences bodily stress systems and therefore contributes to disease.

There is extensive evidence that stress at work, as measured by the DCM, increases the risk of cardiovascular disease (CVD) [17-19]. Particularly the association between the DCM and coronary heart disease (CHD) is shown to be strong and consistent [20, 21]. Also, stress-reduction interventions in the workplace based on the DCM have been efficient [22]. However, less is known about whether the DCM is associated with the risk of stroke, as only a few studies have focused on stroke as a specific CVD outcome, and the results are seemingly inconsistent [23-30]. Whether the impact of work stress varies between stroke subtypes or among women and men is unclear.

The mechanisms linking job strain to increased risk of CVD are suggested to be both direct, through the activation of neuroendocrine stress pathways, and indirect through unhealthy behaviours such as smoking, physical inactivity, or poor eating habits [31]. Review studies report a strong and consistent evidence for an association between job strain and CVD across study designs and populations [18, 19]. Metaanalyses based on observational data report an average 50\% excess risk for $\mathrm{CHD}$ among employees facing work stress [21]. However, these results are mainly valid for men as studies involving women are few and the results tend to be less consistent for women. Some researchers even suggest that work stress may be a less powerful predictor of CHD among women than men [21]. With the focus on working women, the purpose of the present paper was to review the current research into the DCM in relation to stroke and to scrutinize potential gender differences.

\section{Methods}

A literature search was performed that sought to identify available observational studies that examine the DCM in relation to stroke. Study selection was based on five inclusion criteria: (i) study sample includes women workers; (ii) exposure to job strain or at least one of the main components of the DCM is measured - that is, psychological demands or job control; (iii) the reported outcome is either stroke or a CVD outcome that includes stroke; (iv) study design is either a prospective cohort, a case-control, or a cross-sectional study; and (v) the study is published in English in a peer-reviewed journal. The search period ranged from December 1999 to August 2012. Four electronic databases (PubMed, Scopus, PsychInfo, and Web of Science) were searched. In addition, information was gathered through communication with specialists at international conferences of Work Environment and Cardiovascular Disease (http://www.icohweb.org/).

Initially, 311 titles and abstracts were identified. All papers that reported empirical findings of the association between the DCM or its components and stroke or strokerelated outcomes were assessed by the author for relevance and methodological quality applying guidelines used in previous research [32]. The main reason for excluding studies $(n=303)$ was that they did not include stroke as an outcome or did not separate stroke from other CVD. One study solely based on men was excluded as it did not match the inclusion criteria [33]. Another study was excluded because it did not report independent associations for the DCM in relation to stroke, but in combination with social support [34].

\section{Results}

In total, eight published peer-reviewed studies from three countries fulfilled the inclusion criteria and were further analysed (see Table 1 for an overview) [23-29]. One study is from Finland [28], three from Japan [23, 29, 30], and four from Sweden [24-27]. Seven studies are prospective cohort studies and one is a cross-sectional case-control study. Two studies are based on women only [24, 28], the case-control study combines women and men [25], and five studies perform separate analyses for women and men $[23,26,27$, 29, 30].

\subsection{Assessment of the Demand-Control Model and Stroke End Points. In six studies, psychological demands and job control are self-reported and assessed by established questionnaires for the DCM in native language [23-25, 28-30]. Two studies use a job exposure matrix (JEM) that assesses job control on occupational level $[26,27]$. The items for measuring psychological demands and job control are not always the same in the different questionnaires. For instance, the two commonly used questionnaires for assessing the DCM- the Demand-Control Questionnaire (DCQ) and the Job Content Questionnaire (JCQ) — differ somewhat as the DCQ is a shorter version on the JCQ [17]. The JEM assesses demands and control on occupational level, which on one hand eliminates the potential self-report bias, but on the other hand the JEM presents somewhat crude associations}




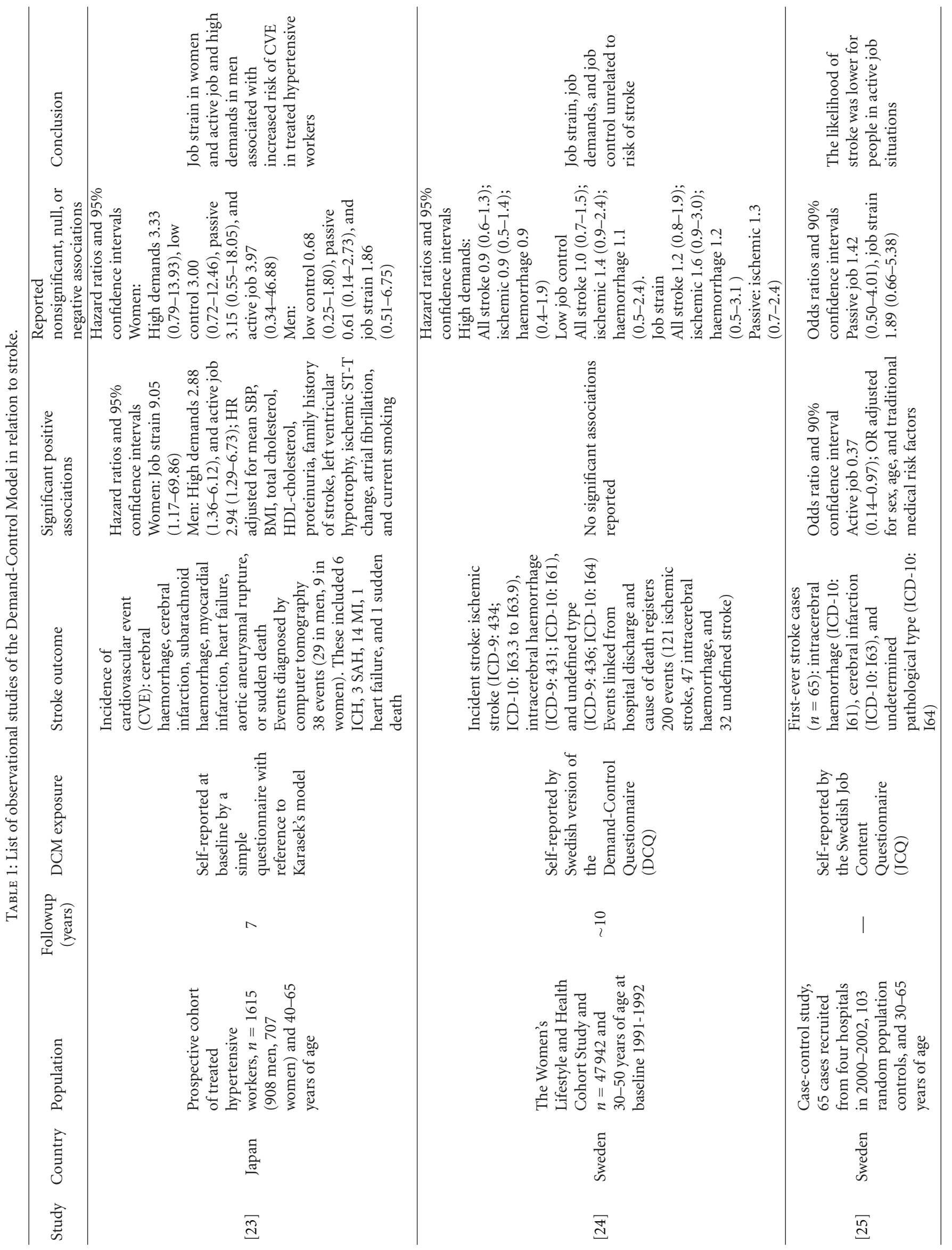




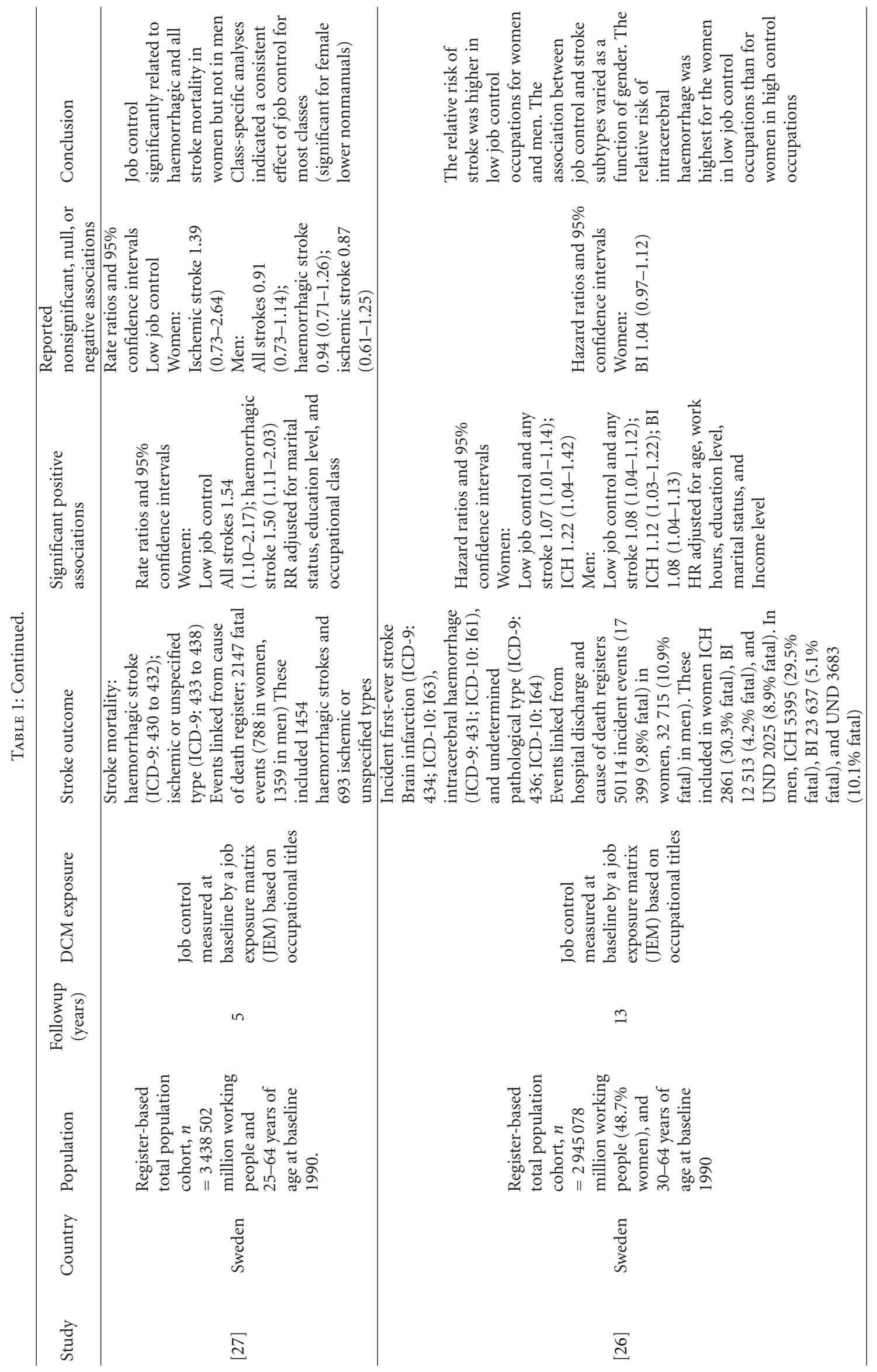




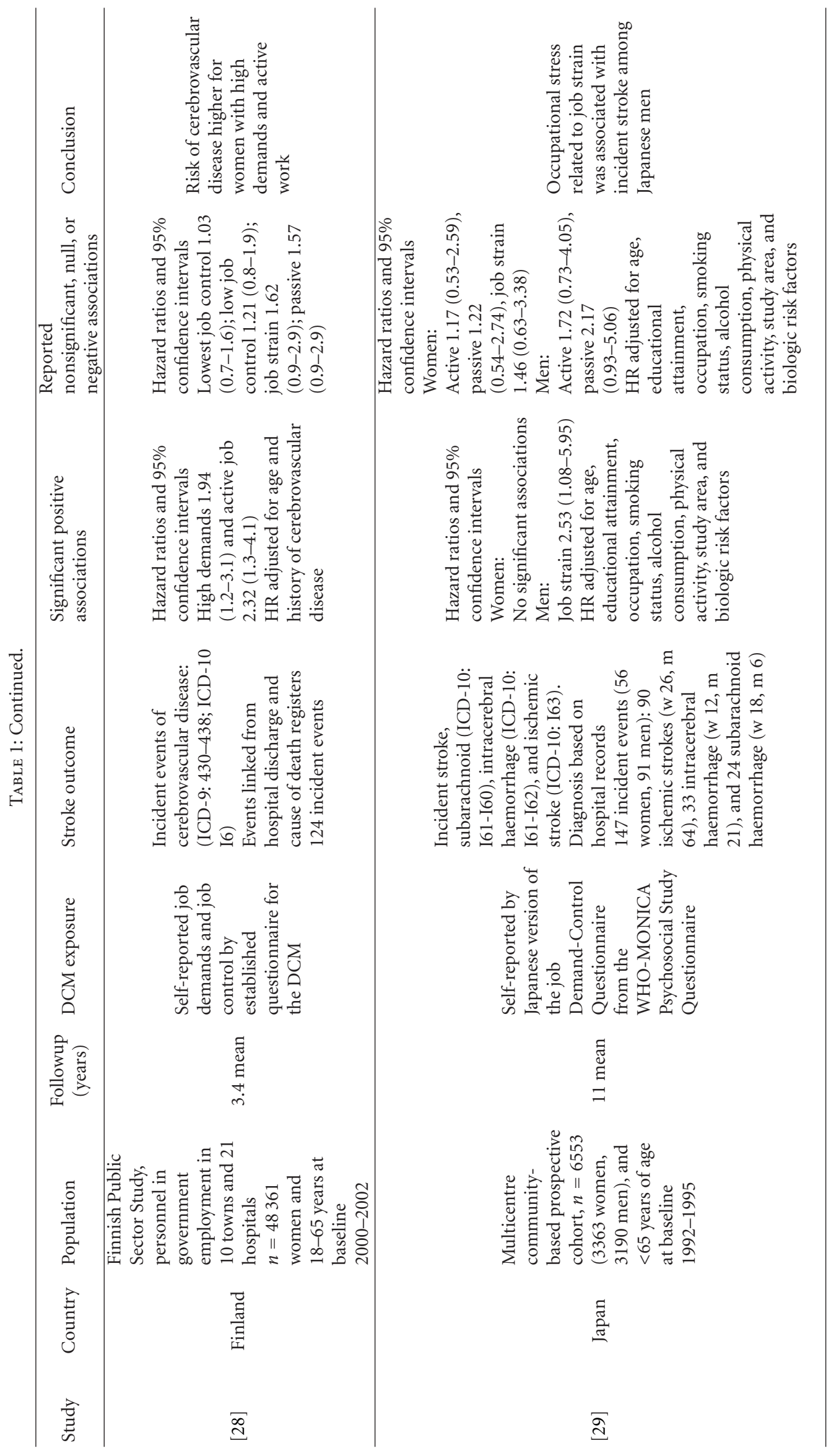




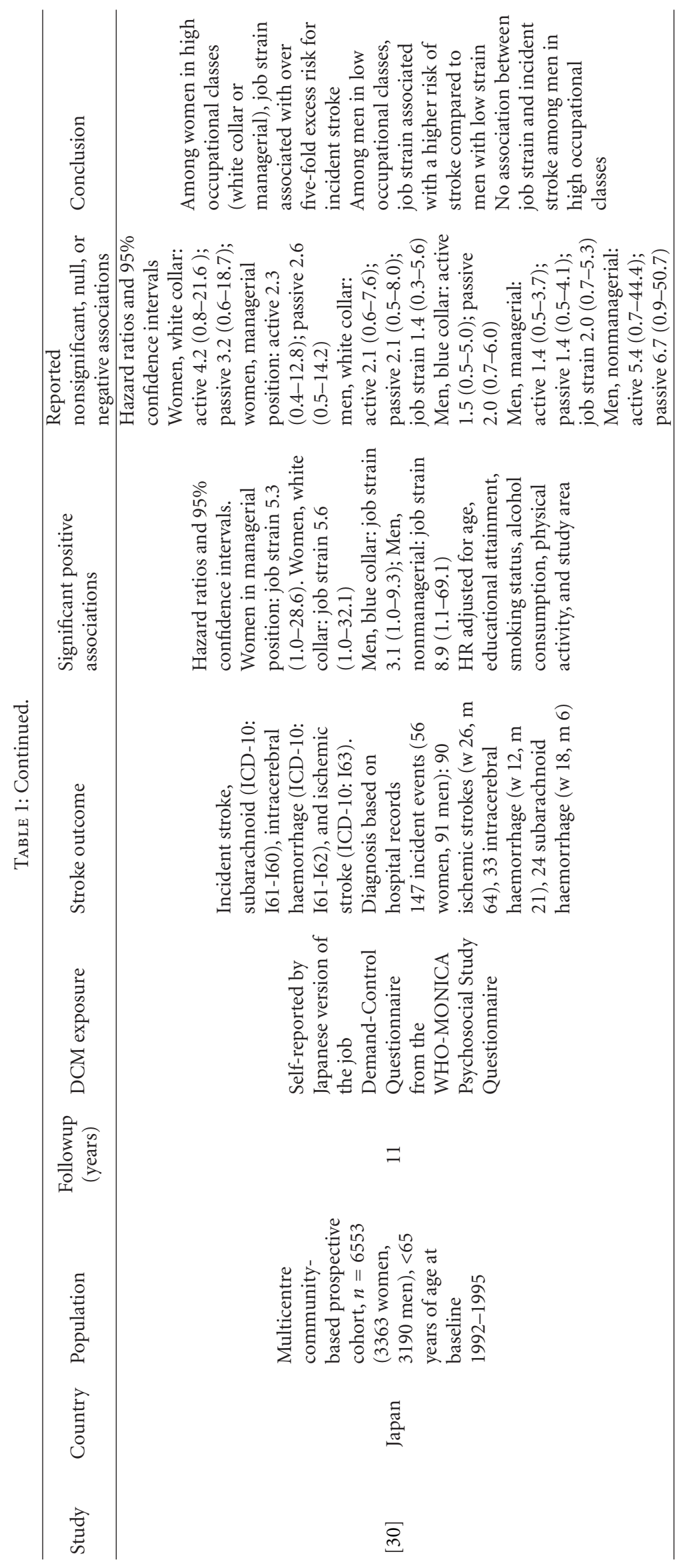


as it assumes that every person with the same occupation has the same level of demands and job control.

Information on stroke incidence and mortality is linked to the cohorts from national routine registers (hospital discharge register and/or causes of death register) in the studies from the Nordic countries where population registers are widely used in research. Stroke diagnoses are based on ICD (International Classification of Diseases) codes, yet the ICD codes that are used for defining the stroke end point vary across the studies. In the studies from Japan, the cohort participants are asked yearly whether they have suffered a stroke event. If so, then all the medical records are reviewed and the stroke diagnose is determined according to international guidelines.

3.2. Psychological Demands. One of the Japanese studies reports an increased risk of cardiovascular events, including stroke, in men facing high psychological demands at work (hazard ratio (HR) 2.88 (95\% CI 1.36-6.12)) compared to those with low demands [23]. The estimate is rigorously adjusted for biomedical risk factors for stroke. The association is significant when women and men (HR 2.63 (1.36-5.22)) are studied together, but not when women are studied separately (HR 3.33 (0.79-13.93)). However, there are only a few cardiovascular events among women with high demands suggesting that low statistical power may influence the nonsignificant results in women.

In a large sample of women working in the public sector in Finland, the risk of cerebrovascular disease is increased among those women facing the highest demands (HR 1.94 (1.2-3.1)) compared to those women with low demands [28]. The estimate is adjusted only for age and previous stroke, which makes potential confounding an issue. There is a clear gradient by psychological demands in relation to the risk of cerebrovascular disease ( $P$ for linear trend 0.0004$)$ and the population attributable fraction for high job demands is large (14.9\%).

3.3. Job Control. Two studies from Sweden based on total population register data investigate the association between job control and risk of stroke in the working population $[26,27]$. In relation to first-ever incident stroke (fatal or nonfatal), both women and men in occupations with low job control have an increased risk of stroke (HR 1.07 (1.01-1.14) in women, 1.08 (1.04-1.12) in men) compared to those in occupations with high job control, adjusted for covariates. As regards to ischemic stroke, the results are significant only in men. However, women facing low job control have a greater risk of intracerebral haemorrhage (HR 1.22 (1.041.42)) than women with high job control, and the hazard ratio is larger in women than in men (HR 1.12 (1.03-1.22)). Analyses are adjusted for age, work hours, education level, income level, and marital status. Regarding mortality from stroke, the results are significant only in women showing that low job control is associated with an increased risk of mortality from any type of stroke (ischemic or haemorrhagic HR 1.54 (1.10-2.17)) and from haemorrhagic stroke (HR $1.50(1.11-2.03))$. The risk estimates are adjusted for marital status, education level, and occupational class. Additional analyses show that the impact of low job control on stroke mortality is consistent in women in all occupational classes (nonmanuals and manuals). Thus, low job control may be a more powerful predictor of stroke in women than in men and particularly of haemorrhagic stroke. Results from Japan are in line with this notion as low job control is associated with an increased risk of cardiovascular events in women (HR 3.00 $(0.72-12.46)$ ), but with a decreased risk in men (HR 0.68 $(0.25-1.80))$, yet the estimates are nonsignificant [23].

3.4. Job Strain and Other Work Situations. While one of the Japanese studies reports a significant association between job strain and risk of stroke in women (HR 9.05 (1.1769.86)) compared to low strain, but not in men (HR $1.86(0.51-6.75))$ [23], the other Japanese study reports a significant association of job strain and stroke risk in men (HR $2.53(1.08-5.94)$ ) compared to low strain, but not in women (HR 1.46 (0.63-3.38)) [29]. However, the samples of the studies differ remarkably as one of them includes employees from small and medium sized enterprises [23], and the other one includes a large share of farming, forestry, and fishery workers [29]. It is plausible that the working conditions are notably different for employed women and women working, for instance, in the fishery industry. When stratifying the analyses by occupational class, job strain is significantly associated with increased stroke risk among white-collar women (HR $5.6(1.0-32.1)$ ) and among women in managerial position (HR $5.3(1.0-28.6)$ ) compared to their reference categories, respectively [30]. In men, these associations are not found, but instead men exposed to job strain in low occupational classes (blue-collar or non managerial) have an increased risk of stroke. Moreover, job strain is associated with an increased risk for stroke in 5 of the included studies $[23-25,28,29]$, but only the findings mentioned above are significant.

Active work is associated with an increased risk of cardiovascular events in men (HR 2.94 (1.29-6.73)) in Japan [23]. The results for women are in line with those of men, but the estimate is nonsignificant (HR 3.97 (0.34-46.88)). In Finland, active work is associated with an increased risk of cerebrovascular disease in women working in the public sector (HR 2.32 (1.3-4.1)) [28]. In Sweden, however, a casecontrol study reports that the likelihood of stroke is lower for people in active work situations (OR 0.37 (90\% CI 0.14$0.97)$ ). Yet, the estimate is uncertain and barely significant with $90 \%$ confidence intervals. For passive work, most of the included studies report an increased risk of stroke both in women and men, but the majority of the associations are nonsignificant [23-25, 28-30].

One study of middle-aged women in Sweden reports that work stress as measured by the DCM is unrelated to the risk of stroke [24]. The study sample includes a remarkably larger proportion of women with higher education ( $>13$ years) and a smaller proportion of women with lower education $(<9$ years) than the general population of middle-aged women in Sweden during the same time period [26, 27]. Thus, the sample is not representative for women in Sweden. Moreover, 
the nonresponse rate (49\%) is considerably high, and the number of stroke events is low, particularly the number of intracerebral haemorrhage (47 events). Taken together, these limitations may influence the nonsignificant results.

3.5. Gender Differences. One of the Japanese studies reports generally higher risk estimates in women than in men for the associations of the DCM and stroke, but most of the estimates are nonsignificant for women [23]. The other Japanese study presents the type of results that are usually found in studies of the DCM in relation to CHD, that is, the results tend to be similar in women and men, but the risk estimates are lower and nonsignificant in women [29]. Yet the third Japanese study highlights gender differences in work stress by occupational class as women in high occupational classes exposed to job strain have a higher risk for stroke compared to women with low strain [30]. In men, on the contrary, job strain was associated with an increased risk of stroke among those in low occupational classes but not among those men in high occupational classes. In the total population studies from Sweden, low job control is associated with an increased risk of mortality from stroke in women across occupational classes (nonmanual and manual), but not in men, and the risk of incident intracerebral haemorrhage is actually higher in women facing low job control than in men $[26,27]$. Thus, there is some evidence that work stress, as measured by the DCM, may be a more powerful predictor of stroke in women than in men $[23,26,27]$.

\section{Discussion}

4.1. Main Conclusions from the Literature Review. With a focus on working women, this paper reviewed the reserach into the DMC in relation to stroke and scrutinized potential gender differences. Based on the studies reviewed in this paper, there is some evidence that high psychological demands, low job control, and job strain are associated with increased stroke risk in women as well as in men. For the case of stroke, work stress might actually be a more powerful predictor among women than men. However, more research from a gender perspective is urgently needed to strengthen the case. The results vary across the included studies regarding which component of the model-that is, psychological demands or job control-or which of the work situations defined by the DCM are associated with the increased risk of stroke. High psychological demands, low job control, and job strain were all associated with an increased risk of stroke in working women.

Based on the four studies that performed separate analyses for women and men, the results suggest that there is some evidence that work stress may be a more powerful predictor of stoke in women than in men. Particularly low job control seems to be a more severe work environment factor for women's risk of stoke than men's. Regarding work stress and stroke subtypes, only two total population studies were large enough to study stroke subtypes separately without encountering power problems in terms of too few stroke events contributing to nonsignificant associations [26,
27]. Based on these two total population studies, it seems that the association between work stress and intracerebral haemorrhage is more pronounced in women than the one with ischemic stroke when compared to men.

4.2. Strength and Weaknesses of the Literature Review. No previous literature review or systematic review has focused specifically on the association of the DCM and stroke. This review aimed in the first place to establish the present state of research into work stress and stroke in working women. Thus, the aim was not to perform a full systematic review of the field, but rather to take a first step in such a scientific endeavour $[18,21]$. No meta-analyses or pooled analyses were performed that would provide summary estimates for the association between the DCM or its components and the risk of stroke in women and men. Such analyses are a challenge when the included studies use various ways of operationalizing the exposure and defining the outcome.

4.3. Suggestions for Future Research. More studies are needed that investigate the association between work stress and stroke. Studies that use uniform definitions and methodologies for assessing exposure and outcome are encouraged as this would greatly facilitate the accomplishment of future systematic reviews and meta-analyses. The present paper indicates that differences in women's and men's working life circumstances play a role for their risk of stroke in different geographical and cultural contexts. Therefore, genderspecific analyses are crucial. More studies from different parts of the world and from different contexts are needed, particularly studies from fast growing and expansive economies such as the BRIC countries, where the middle class is huge and social inequalities in health are more pronounced than in developed countries [35-37].

4.4. Burden of Stroke and Policy Implications. Stroke and heart disease are predicted to be the leading cause of death and disability worldwide by 2020 , and the number of fatalities is projected to increase to over 24 million a year by 2030 [38]. Moreover, stroke incidence is expected to increase in an epidemic way, especially in low and middle income countries, due to aging populations and better emergency care [39]. Nevertheless, no matter the advances in high technology medicine, any major reduction in deaths and disability from stroke will mainly come from decreasing social inequalities in health and from prevention, not just cure $[10,40,41]$. Societal factors, such as urbanisation and rapid socioeconomic changes, affect the risk of stroke as they lead to changes in people's lifestyle, working conditions and work-related stress, altered food habits, and the risk of developing hypertension, diabetes, and hyperlipidaemia [42]. Obesity, poor diets, smoking, and physical inactivity, the leading risk factors of stroke, are being seen at an alarmingly early age, and there are clear socioeconomic gradients in these behaviours. Reducing work-related stress has a potential to contribute to a reduced risk of stroke in working populations. Stroke is indeed a preventable disease and the time for action is now. 


\section{Acknowledgments}

The author gratefully acknowledges the Swedish Council for Working Life and Social Research (FAS, http://www.fas.se/), Grant no. 2007-0539, for financing this paper. The paper was presented at the International Conference on Gender \& Development in the World of Work, held in Jhansi, India in March 2010, and was first published in Sahaya, A., Kaishta, S. and Patel, V. (Eds.), Gender \& Development, New Delhi: The Women Press, 2011. This updated version is reprinted with the kind permission of the editors.

\section{References}

[1] World Health Organization and Commission on Social Determinants of Health, Closing the Gap in a Generation: Health Equity Through Action on the Social Determinants of Health, World Health Organization, Geneva, Switzerland, 2008.

[2] J. Benach, O. Solar, V. Santana, A. Castedo, H. Chung, and C. Muntaner, "A micro-level model of employment relations and health inequalities," International Journal of Health Services, vol. 40, no. 2, pp. 223-227, 2010.

[3] I. Lundberg, T. Hemmingsson, and C. Hogstedt, Eds., Work and Social Inequalities in Health in Europe, P.I.E. Peter Lang, Bruxelles, Belgium, 2007.

[4] J. Medin, Stroke among people of working age: from a public health and working life perspective [Ph.D. thesis], Linköping University, Linköping, Sweden, 2006.

[5] K. Daniel, C. D. A. Wolfe, M. A. Busch, and C. Mckevitt, "What are the social consequences of stroke for working-aged adults? A systematic review," Stroke, vol. 40, no. 6, pp. e431-e440, 2009.

[6] P. Noone, "Shift work risk of stroke and metabolic syndrome," Occupational Medicine, vol. 59, no. 7, p. 521, 2009.

[7] A. M. Cox, C. McKevitt, A. G. Rudd, and C. D. A. Wolfe, "Socioeconomic status and stroke," The Lancet Neurology, vol. 5, no. 2, pp. 181-188, 2006.

[8] O. Ghatnekar, U. Persson, E. L. Glader, and A. Terént, "Cost of stroke in Sweden: an incidence estimate," International Journal of Technology Assessment in Health Care, vol. 20, no. 3, pp. 375380, 2004.

[9] P. Appelros, B. Stegmayr, and A. Terent, "Sex differences in stroke epidemiology: a systematic review," Stroke, vol. 40, no. 4, pp. 1082-1090, 2009.

[10] J. Mckay, G. A. Mensah, K. Greenlund, S. Mendis, and World Health Organization, The Atlas of Heart Disease and Stroke, World Health Organization, Geneva, Switzerland, 2005.

[11] A. Członkowska and A. Kobayashi, "Does gender exert influence on stroke?" Neurologia i Neurochirurgia Polska, vol. 37, supplement 3, pp. 51-62, 2003.

[12] S. Sacco, D. Cerone, and A. Carolei, "Gender and stroke: acute phase treatment and prevention," Functional Neurology, vol. 24, no. 1, pp. 45-52, 2009.

[13] M. J. O’Donnell, D. Xavier, L. Liu et al., "Risk factors for ischaemic and intracerebral haemorrhagic stroke in 22 countries (the INTERSTROKE study): a case-control study," The Lancet, vol. 376, no. 9735, pp. 112-123, 2010.

[14] N. H. Eller, B. Netterstrøm, F. Gyntelberg et al., "Work-related psychosocial factors and the development of ischemic heart disease: a systematic review," Cardiology in Review, vol. 17, no. 2, pp. 83-97, 2009.
[15] R. A. Karasek and T. Theorell, Healthy Work: Stress, Productivity and Reconstruction of Working Life, Basic Books, New York, NY, USA, 1990.

[16] J. Siegrist and T. Theorell, "Socio-economic position and health. The role of work and employment," in Social Inequalities in Health, J. Siegrist and M. Marmot, Eds., pp. 73-100, Oxford University Press, Oxford, UK, 2006.

[17] P. Schnall, K. Belkic, P. Landsbergis, and D. Baker, Eds., The Workplace and Cardiovascular Disease. Occupational Medicine: State of the Art Reviews 15:1, Hanley \& Belfus, Philadephia, $\mathrm{Pa}, \mathrm{USA}, 2000$.

[18] K. L. Belkic, P. A. Landsbergis, P. L. Schnall, and D. Baker, "Is job strain a major source of cardiovascular disease risk?" Scandinavian Journal of Work, Environment and Health, vol. 30, no. 2, pp. 85-128, 2004.

[19] E. M. Backé, A. Seidler, U. Latza, K. Rossnagel, and B. Schumann, "The role of psychosocial stress at work for the development of cardiovascular diseases: a systematic review," International Archives of Occupational and Environmental Health, vol. 85, no. 1, pp. 67-79, 2012.

[20] H. Kuper, M. Marmot, and H. Hemingway, "Systematic review of prospective cohort studies of psychosocial factors in the etiology and prognosis of coronary heart disease," Seminars in Vascular Medicine, vol. 2, no. 3, pp. 267-314, 2002.

[21] M. Kivimäki, M. Virtanen, M. Elovainio, A. Kouvonen, A. Väänänen, and J. Vahtera, "Work stress in the etiology of coronary heart disease- - meta-analysis," Scandinavian Journal of Work, Environment and Health, vol. 32, no. 6, pp. 431-442, 2006.

[22] R. Bourbonnais, C. Brisson, A. Vinet, M. Vézina, B. Abdous, and M. Gaudet, "Effectiveness of a participative intervention on psychosocial work factors to prevent mental health problems in a hospital setting," Occupational and Environmental Medicine, vol. 63, no. 5, pp. 335-342, 2006.

[23] S. Uchiyama, T. Kurasawa, T. Sekizawa, and H. Nakatsuka, "Job strain and risk of cardiovascular events in treated hypertensive Japanese workers: hypertension follow-up group study," Journal of Occupational Health, vol. 47, no. 2, pp. 102111, 2005.

[24] H. Kuper, H. O. Adami, T. Theorell, and E. Weiderpass, "The socioeconomic gradient in the incidence of stroke: a prospective study in middle-aged women in Sweden," Stroke, vol. 38, no. 1, pp. 27-33, 2007.

[25] J. Medin, K. Ekberg, A. Nordlund, and J. Eklund, "Organisational change, job strain and increased risk of stroke? A pilot study," Work, vol. 31, no. 4, pp. 443-449, 2008.

[26] S. Toivanen, "Job control and the risk of incident stroke in the working population in Sweden," Scandinavian Journal of Work, Environment and Health, vol. 34, no. 1, pp. 40-47, 2008.

[27] S. Toivanen and Ö. Hemström, "Is the impact of job control on stroke independent from socioeconomic status? A large-scale study of the Swedish working population," Stroke, vol. 39, no. 4, pp. 1321-1323, 2008.

[28] M. Kivimäki, D. Gimeno, J. E. Ferrie et al., "Socioeconomic position, psychosocial work environment and cerebrovascular disease among women: the Finnish public sector study," International Journal of Epidemiology, vol. 38, no. 5, pp. 12651271, 2009.

[29] A. Tsutsumi, K. Kayaba, K. Kario, and S. Ishikawa, "Prospective study on occupational stress and risk of stroke," Archives of Internal Medicine, vol. 169, no. 1, pp. 56-61, 2009. 
[30] A. Tsutsumi, K. Kayaba, and S. Ishikawa, "Impact of occupational stress on stroke across occupational classes and genders," Social Science and Medicine, vol. 72, no. 10, pp. 1652 1658, 2011.

[31] K. Orth-Gomér, C. Albus, N. Bagés et al., "Psychosocial considerations in the European guidelines for prevention of cardiovascular diseases in clinical practice: third joint task force," International Journal of Behavioral Medicine, vol. 12, no. 3, pp. 132-141, 2005.

[32] S. R. Stock, "Workplace ergonomic factors and the development of musculoskeletal disorders of the neck and upper limbs: a meta-analysis," American Journal of Industrial Medicine, vol. 19, no. 1, pp. 87-107, 1991.

[33] M. Kivimäki, T. Theorell, H. Westerlund, J. Vahtera, and L. Alfredsson, "Job strain and ischaemic disease: does the inclusion of older employees in the cohort dilute the association? The WOLF Stockholm Study," Journal of Epidemiology and Community Health, vol. 62, no. 4, pp. 372-374, 2008.

[34] L. André-Petersson, G. Engström, B. Hedblad, L. Janzon, and M. Rosvall, "Social support at work and the risk of myocardial infarction and stroke in women and men," Social Science and Medicine, vol. 64, no. 4, pp. 830-841, 2007.

[35] C. S. Lopes, R. Araya, G. L. Werneck, D. Chor, and E. Faerstein, "Job strain and other work conditions: relationships with psychological distress among civil servants in Rio de Janeiro, Brazil," Social Psychiatry and Psychiatric Epidemiology, vol. 45, no. 3, pp. 345-354, 2010.

[36] G. Salavecz, T. Chandola, H. Pikhart et al., "Work stress and health in Western European and post-communist countries: an East-West comparison study," Journal of Epidemiology and Community Health, vol. 64, no. 1, pp. 57-62, 2010.

[37] W. Xu, Y. Zhao, L. Guo, Y. Guo, and W. Gao, "The association between effort-reward imbalance and coronary atherosclerosis in a Chinese sample," American Journal of Industrial Medicine, vol. 53, no. 7, pp. 655-661, 2010.

[38] World Health Organization, World Health Statistics, World Health Organization, Geneva, Switzerland, 2008.

[39] A. D. Lopez and C. C. J. L. Murray, "The global burden of disease, 1990-2020," Nature Medicine, vol. 4, no. 11, pp. 12411243, 1998.

[40] P. K. Asplund, "What MONICA told us about stroke," The Lancet Neurology, vol. 4, no. 1, pp. 64-68, 2005.

[41] P. A. Lotufo, "Stroke in Brazil: a neglected disease," Sao Paulo Medical Journal, vol. 123, no. 1, pp. 3-4, 2005.

[42] J. D. Pandian, V. Srikanth, S. J. Read, and A. G. Thrift, "Poverty and stroke in India: a time to act," Stroke, vol. 38, no. 11, pp. 3063-3069, 2007. 


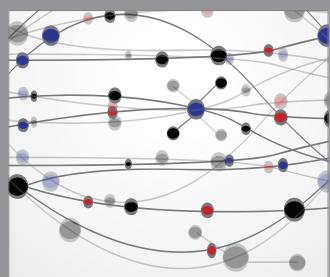

The Scientific World Journal
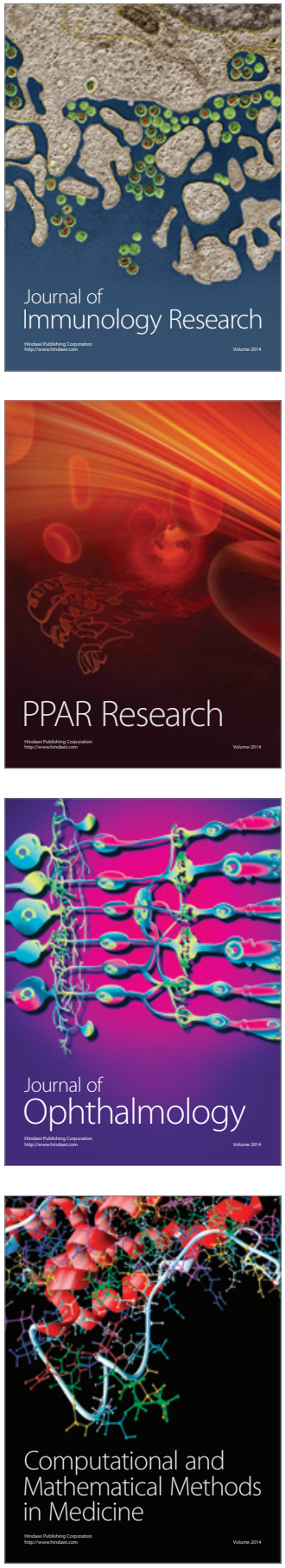

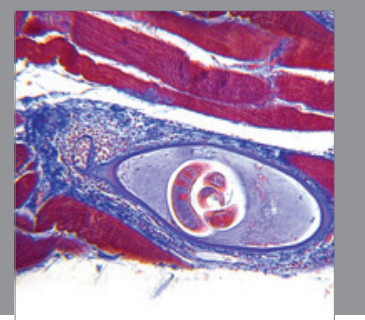

Gastroenterology

Research and Practice
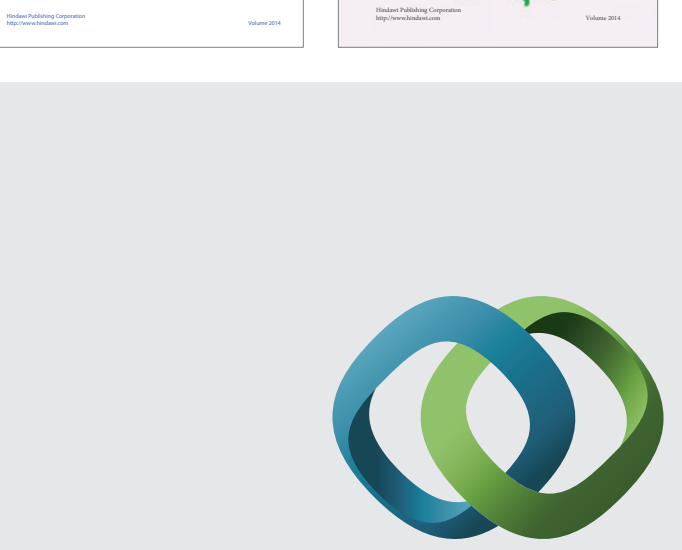

\section{Hindawi}

Submit your manuscripts at

http://www.hindawi.com
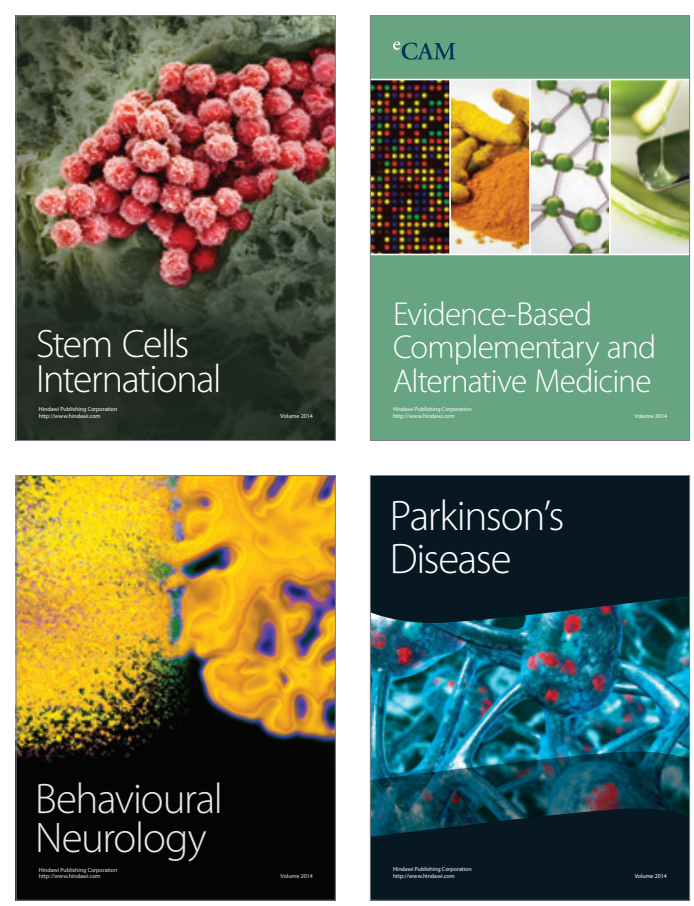

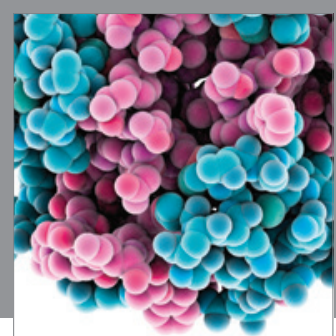

Journal of
Diabetes Research

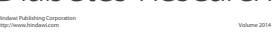

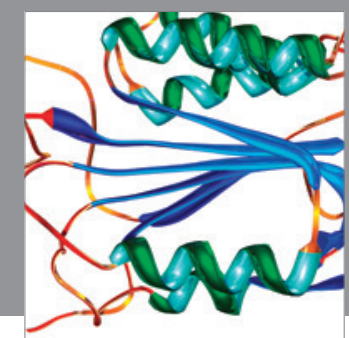

Disease Markers
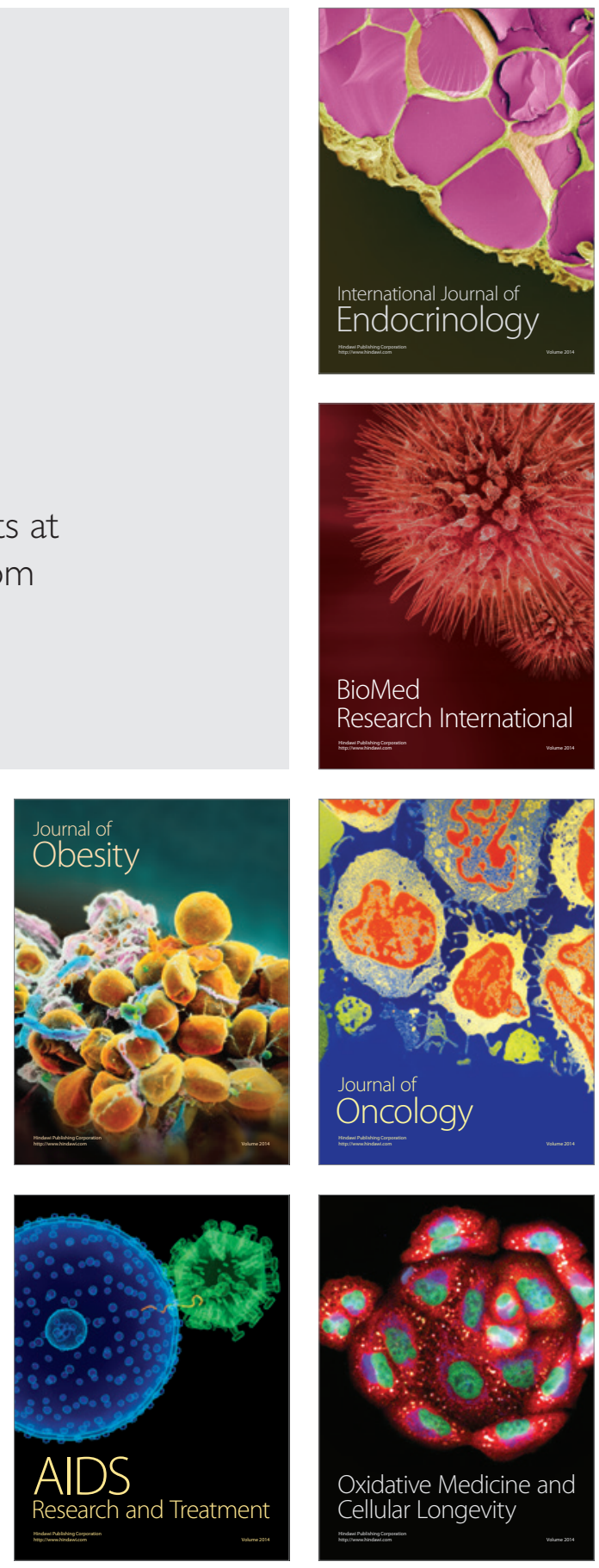